\title{
Síndrome de Netherton: el caso de un recién nacido con insuficiencia respiratoria
} Netherton syndrome: A neonatal case with respiratory insufficiency

\author{
Dra. Emel Okulua, Dr. Gaffari Tunc ${ }^{a}$, Prof. Dr. Omer Erdevea, Dra. Yelda Mumcu', Prof. Dra. Begum Atasay ${ }^{a}$, \\ Prof. Dr. Erdal Ince y Prof. Dra. Saadet Arsan ${ }^{a}$
}

\section{RESUMEN}

El síndrome de Netherton (SN) es una enfermedad autosómica recesiva, muy poco frecuente, que se caracteriza por la presencia de eritrodermia ictiosiforme congénita, anomalías capilares y manifestaciones atópicas. Este síndrome es consecuencia de una mutación recesiva en el gen SPINK5. Las manifestaciones del síndrome de $\mathrm{SN}$ varían considerablemente entre las personas que lo padecen. Aquí informamos el caso de un recién nacido que presentaba insuficiencia respiratoria grave, hipotermia y eritrodermia, al que se le diagnosticó SN, confirmado mediante pruebas genéticas moleculares.

Palabras clave: recién nacido, síndrome de Netherton, insuficiencia respiratoria.

http:/ / dx.doi.org/10.5546/ aap.2018.e609

Texto completo en inglés:

http: / / dx.doi.org/10.5546/ aap.2018.eng.e609

Cómo citar: Okulu E, Tunc G, Erdeve O, et al. Síndrome de Netherton el caso de un recién nacido con insuficiencia respiratoria. Arch Argent Pediatr 2018;116(4):e609-e611.

\section{INTRODUCCIÓN}

El síndrome de Netherton es una enfermedad autosómica recesiva grave, muy poco frecuente, que se caracteriza por la presencia de eritrodermia ictiosiforme congénita, una anomalía capilar conocida como "tricorrexis invaginata" y manifestaciones atópicas. Algunos informes recientes muestran que el gen SPINK5 codifica el inhibidor linfoepitelial tipo Kazal (LEKTI),

a. Departamento de Pediatría, División de Neonatología, Facultad de Medicina de Ankara Üniversitesi, Ankara, Turquía.

b. Unidad de Cuidados Intensivos Neonatales, Ankara TOBB ETU Hospital, Ankara, Turquía.

c. Departamento de Pediatría, División de Infectología Pediátrica, Facultad de Medicina de Ankara Üniversitesi, Ankara, Turquía.

Correspondencia: Dra. Emel Okulu: emelokulu@gmail.com

Financiamiento: Ninguno.

Conflicto de intereses: Ninguno que declarar.

Recibido: 21-9-2017

Aceptado: 31-1-2018 una proteína localizada en la capa granular y la capa espinosa más externa de la epidermis, y también en las capas más diferenciadas de todos los epitelios estratificados. ${ }^{1,2}$

En el presente documento informamos sobre el caso de un paciente recién nacido con $\mathrm{SN}$, que presentó eritrodermia generalizada e hipotermia, y requirió oxigenación por membrana extracorpórea (ECMO por sus siglas en inglés).

\section{A propósito de un caso}

Un varón de 3300 g nació con 39 semanas de gestación por cesárea repetida, con puntajes de Apgar de 6 y 8 al minuto y a los 5 minutos, respectivamente. Este bebé fue el segundo hijo de padres no consanguíneos, tras un embarazo sin complicaciones. Recibió asistencia respiratoria con presión positiva en la sala de partos. No se observó meconio en el momento del parto. El lactante desarrolló dificultad respiratoria que empeoró en los minutos siguientes, y se lo intubó. Se administró surfactante en dos ocasiones a fin de mejorar la oxigenación debido al aspecto de vidrio esmerilado de la radiografía de tórax. El análisis en serie de los gases en sangre mostró hipoxemia persistente, y el lactante fue derivado a nuestra unidad de cuidados intensivos neonatales (UCIN) para que se evaluara si necesitaba ECMO.

Al ingresar a nuestra UCIN, el lactante presentaba hipotermia grave (temperatura corporal: $32{ }^{\circ} \mathrm{C}$ ) y bradicardia, además de insuficiencia respiratoria. Se registraron cabello, cejas y pestañas finos y frágiles, y eritrodermia de tipo psoriasiforme generalizada en todo el cuerpo (Figura 1). Excepto para la hipoxemia, los resultados de laboratorio no eran específicos al momento del ingreso. La ecocardiografía mostraba hipertensión pulmonar leve, sin anomalías estructurales. El examen del cabello mediante microscopía óptica fue notable para la característica de "tricorrexis invaginata", coincidente con el diagnóstico clínico de SN (Figura 2), y las pruebas genéticas moleculares mostraron una mutación homocigota IVS17-1G $>$ A (c.1608-1G>A) del gen SPINK5. 
Fue posible mantener la normotermia del lactante, y al quinto día de vida se lo extubó. El segundo día desarrolló hipernatremia (165 mEq/L, N:133-145 mEq/L), que se resolvió con tratamiento con líquidos intravenosos. El eritroderma exfoliativo mejoró con el uso continuo de aquaphor tópico. Durante el seguimiento, recibió tratamiento con broncodilatadores debido a que presentó síntomas de bronquiolitis, y fue dado de alta a los 25 días de vida con tratamiento tópico de la piel.

En este momento, el bebé tiene cinco meses. Ingresó al hospital con infección vírica de las vías respiratorias bajas y fue tratado con broncodilatadores. Aún presenta eritrodermia generalizada con descamación, para la que recibe tratamiento tópico. Está en el programa de seguimiento del Departamento de Inmunología Pediátrica. Con miras a un próximo embarazo, la familia recibió asesoramiento genético y se les sugirió pedir un diagnóstico genético prenatal.

FIgURA 1. Paciente con cabello fino y eritrodermia

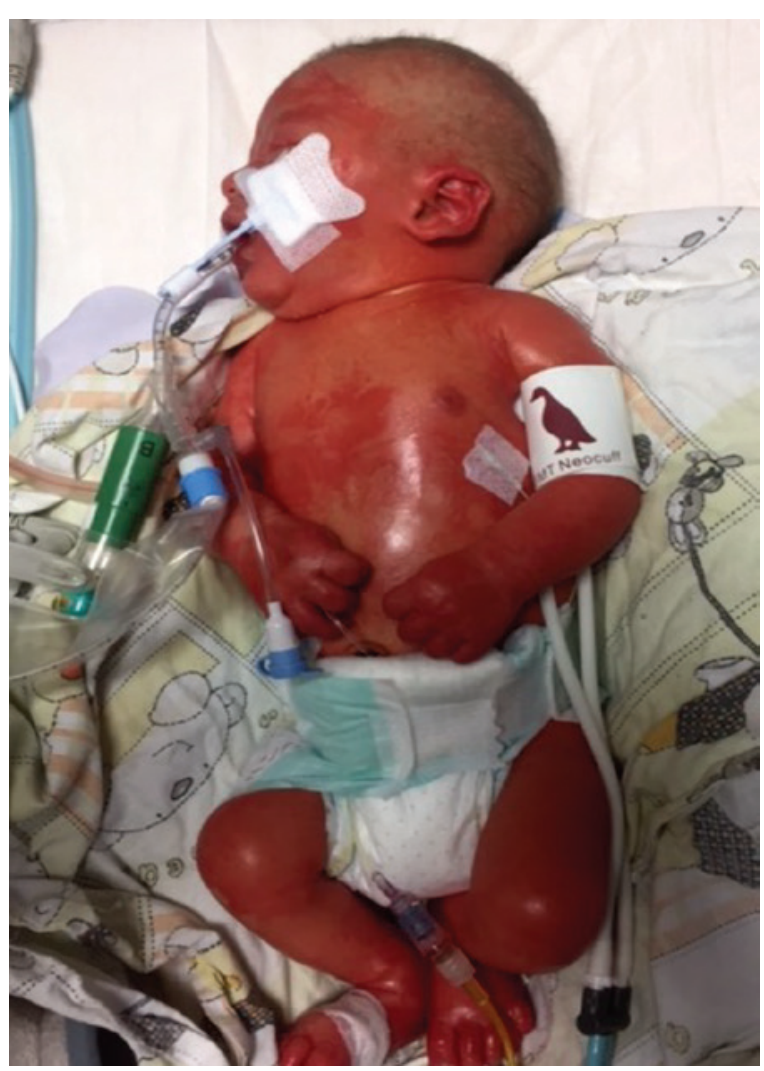

\section{DISCUSIÓN}

El síndrome de Netherton es una enfermedad autosómica recesiva, muy poco frecuente, que se caracteriza por la presencia de anomalías capilares y cutáneas. Se ha calculado su incidencia en 1 cada 200000 , y podría ser la causa del $18 \%$ de los casos de eritrodermia congénita. ${ }^{3} \mathrm{El}$ paciente que describimos aquí presentaba las características típicas del síndrome de Netherton: eritroderma, cabello de bambú, síntomas respiratorios e hipernatremia con mutación del gen SPINK5.

Macknet et al., informaron sobre el caso de un lactante con SN que fue tratado con ECMO por una hipertensión pulmonar persistente que se supuso secundaria a una bronconeumonía debido al líquido amniótico espeso, que contenía células epidérmicas exfoliadas. ${ }^{4}$ Nuestro paciente fue intubado, recibió surfactante enseguida después de nacer y fue derivado a nuestra unidad para recibir tratamiento con ECMO. Dada la hipertensión pulmonar leve, el lactante fue tratado con terapias convencionales. En nuestra opinión, la aspiración de líquido amniótico con células epidérmicas descamadas fue lo que provocó la neumonía y la insuficiencia respiratoria.

El gen causante del síndrome de Netherton se identificó en el cromosoma 5q32; se denomina SPINK5 (inhibidor de una serina proteasa, tipo Kazal-5), y codifica para un inhibidor de las proteasas serinas llamadas LEKTI. ${ }^{2,5}$ Chavanas et al. informaron la primera mutación del SPINK5 $5^{5}$

FIGURA 2. Tricorrexis invaginata del cabello del paciente visto a través de microscopía óptica

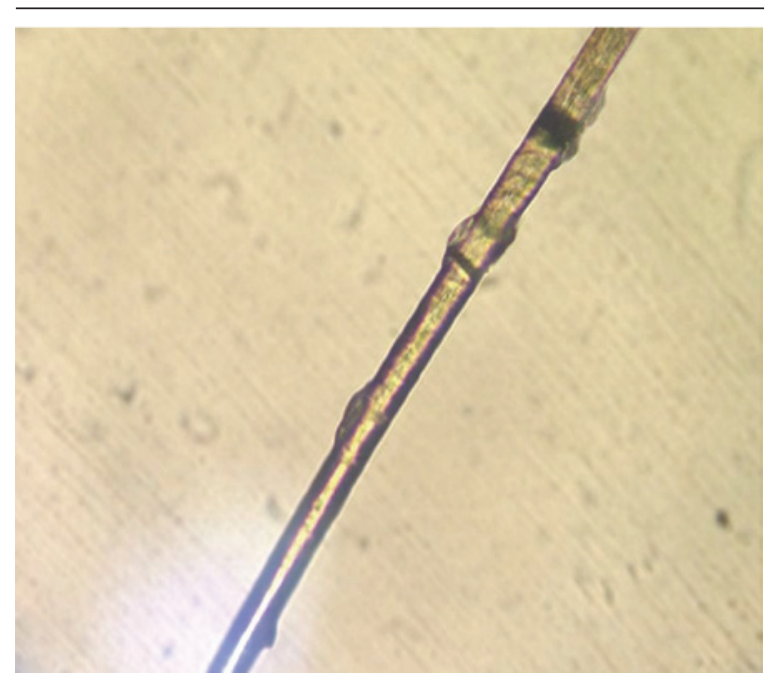


$\mathrm{y}$, hasta hoy, se han registrado 80 mutaciones distintas en regiones exónicas e intrónicas. ${ }^{6}$ Nuestro paciente era homocigoto para la mutación en el sitio de corte y empalme del intrón 17 (1608-1G $\rightarrow$ A). Esta mutación había sido identificada previamente en un paciente francés de 8 años que presentó eritrodermia al nacer, tricorrexis invaginata, manifestaciones atópicas, retraso del crecimiento, infecciones recurrentes y enteropatía. ${ }^{7}$

En la actualidad, no hay tratamientos comprobados ni consensuados. El tratamiento de las lesiones cutáneas consiste en emolientes, antihistamínicos, antibióticos y corticoesteroides locales. ${ }^{6}$ Se han informado casos de éxito cuando se administró tratamiento con anticuerpos monoclonales a pacientes adultos con SN..$^{8,9}$ Nuestro paciente ha recibido tratamiento solo con emolientes y antibacterianos tópicos.

En conclusión, nuestro paciente es uno de los casos muy poco frecuentes que presentan insuficiencia respiratoria al nacer y cuyas características denotan $\mathrm{SN}$, como las anomalías cutáneas y capilares confirmadas con mutación del gen SPINK5. En los recién nacidos, el diagnóstico de síndrome de Netherton es todo un desafío. La enfermedad muestra una amplia variedad de fenotipos clínicos. El diagnóstico precoz es fundamental, dado que esta enfermedad está asociada con complicaciones potencialmente mortales. El diagnóstico prenatal es especialmente importante cuando existen antecedentes familiares de SN y consanguinidad.

\section{REFERENCIAS}

1. Bitoun E, Micheloni A, Lamant L, et al. LEKTI proteolytic processing in human primary keratinocytes, tissue distribution and defective expression in Netherton syndrome. Hum Mol Genet 2003;12(19):2417-30.

2. Chavanas $\mathrm{S}$, Bodemer $\mathrm{C}$, Rochat $\mathrm{A}$, et al. Mutations in SPINK5, encoding a serine protease inhibitor, cause Netherton syndrome. Nat Genet 2000;25(2):141-2.

3. Pruszkowski A, Bodemer C, Fraitag S, et al. Neonatal and infantile erythrodermas: a retrospective study of 51 patients. Arch Dermatol 2000;136(7):875-80.

4. MacknetCA, Morkos A, Job L, etal. Aninfant with Netherton syndrome and persistent pulmonary hypertension requiring extracorporeal membrane oxygenation. Pediatr Dermatol 2008;25(3):368-72.

5. Chavanas S, Garner C, Bodemer C, et al. Localization of the Netherton syndrome gene to chromosome $5 q 32$, by linkage analysis and homozygosity mapping. Am J Hum Genet 2000;66(3):914-21.

6. Sarri CA, Roussaki-Schulze A, Vasilopoulos Y, et al. Netherton syndrome: a genotype-phenotype review. Mol Diagn Ther 2017;21(2):137-52.

7. Bitoun E, Chavanas S, Irvine AD, et al. Netherton syndrome: disease expression and spectrum of SPINK5 mutations in 21 families. J Invest Dermatol 2002;118(2):352-61.

8. Yalcin AD. A case of netherton syndrome: successful treatment with omalizumab and pulse prednisolone and its effects on cytokines and immunoglobulin levels. Immunopharmacol Immunotoxicol 2016;38(2):162-6.

9. Roda A, Mendonça-Senches M, Travassos AR, et al. Infliximab therapy for Netherton syndrome. A case report. JAAD Case Rep 2017;3(6):550-2. 